\title{
Currículo de Medicina e as Competências Propostas pelas Diretrizes Curriculares
}

\section{The Medicine Curriculum and Competences Proposed for Curriculum Guidelines}

\author{
Camila Ament Giuliani dos Santos Franco \\ Marcia Regina Cubas ${ }^{I}$ \\ Renato Soleiman Franco ${ }^{I}$
}

\section{PALAVRAS-CHAVE}

- Educação Médica;

- Competência Profissional;

- Currículo.

\section{KEYWORDS}

- Medical Education;

- Professional Competence;

- Curriculum.

Recebido em: 17/10/2012

Reencaminhado em: 28/06/2013

Aprovado em: 06/02/2014

\begin{abstract}
RESUMO
A educação médica passa por críticas quanto aos métodos de ensino e conteúdos. O motivo para mudanças está em possibilitar maior eficácia na formação, permitindo aos egressos lidar com problemas da sociedade brasileira. Este artigo objetiva analisar o conteúdo dos Planos de Ação das disciplinas do currículo de um curso de Medicina, tendo como referência o perfil do egresso e as competências/habilidades propostas pelas DCN para o curso de Medicina. Na organização e análise do material,foram utilizadas Análise de Conteúdo e estatística simples para descrição de parte dos resultados. As análises foram feitas por disciplinas, por semestres e por fases do curso. Constatou-se que 23 das 28 competências/habilidades estavam presentes.Do total de 70 disciplinas, oito não faziam referência a qualquer competência presente nas DCN, e as outras 62 faziam menção a pelo menos uma competência. O currículo, em sua grande maioria, está pautado por competências/habilidades, com o desenvolvimento gradual destas durante as fases do curso médico. A APS é o grande eixo, que percorre nove dos $12 \mathrm{se}-$ mestres do curso, preocupado com as competências técnicas do egresso, sem se ausentar do papel social da universidade, bem como da relação médico-paciente, do cuidado e do trabalho multiprofissional.
\end{abstract}

\begin{abstract}
Medical education has been the subject of criticisms regarding teaching methods and content. The reason for change is to ensure more efficient training so that graduates are better prepared to deal with problems typical of Brazilian society. This article aims to analyze the content of the action plans for subjects in the curriculum of an undergraduate medicine course, based onthe graduate profile and competences/skills proposed by the National Curriculum Guidelines (DCN) for the medicine course. The material was organized and analyzedthrough the use of content analysis and simple statistics to describe some of the results. The analyses were made per subject, per semester and per stage of the course. It was found that 23 of the 28 competences/skills were present in 62 of 70 subjects. Out ofa total of 70 disciplines,eight did not refer to any competencespecified in the DCN, the other 62 mentioned at least 1 competence.The curriculum is largely based on competences/skills and their gradual development throughout the phases of medical school. Primary Care is a major thrust, covering nine of the 12 semesters; concerned with the technical skills of graduates without ignoringthe social role of the university as well as the doctor-patient relationship, care and multidisciplinary work.
\end{abstract}




\section{INTRODUÇÃO}

A educação médica está passando por críticas quanto aos métodos de ensino e aos conteúdos, vivendo um processo de transformação explicitado nas reformas curriculares em diversas escolas médicas ${ }^{1}$. O motivo de tantas mudanças é garantir maior eficácia na formação e cultivar um egresso médico capaz de lidar com os problemas da sociedade brasileira moderna ${ }^{2}$.

Ao traçar um panorama histórico, notam-se marcos relevantes, retratados pela evolução da educação médica em três fases $^{3}$ : a primeira, de 1950 a 1970, de planificação por objetivo, direcionada à gestão; a segunda fase, de 1970 a 1990, marcada pela busca da pertinência, ou seja, de um médico em concordância com as necessidades locais de saúde, quantitativa e qualitativamente; e a terceira fase, a partir dos anos de 1990 até os dias atuais, que busca o impacto da educação médica sobre a saúde da população.

Uma das estratégias propostas para modificação do cenário surge em 2001, quando o Ministério da Educação e Cultura, por meio do Conselho Nacional de Saúde / Centro de Ensino Superior, propõe aos cursos de Medicina um currículo baseado em competências e estabelece diretrizes, incluindo seis competências e habilidades gerais e 22 específicas para o egresso. Coube às universidades e faculdades adequarem seus currículos a essas diretrizes ${ }^{4}$.

Entre os pontos-chave das diretrizes tem-se o aprendizado por competências, a formação de um egresso com uma compreensão ampliada de saúde e uma visão social pertinente. Além da abordagem por competência, as Diretrizes Curriculares Nacionais (DCN) valorizam, entre outros, um egresso com um perfil atrelado a um cuidado integral, com uma ampla visão de saúde e doença, e que considere o indivíduo não fragmentado, bem como seu contexto, e com conhecimento da realidade em que atua ${ }^{4}$.

Pode-se destacar como um objetivo da formação por competência uma prática eficaz, capaz não somente de solucionar problemas, mas também de melhorar os contextos sociais por meio de uma gestão responsável e uso eficiente dos recursos 5 . No entanto, a grande influência que o mercado de trabalho em um mundo globalizado exerce sobre a universidade sempre está presente 6 .

De fato, elementos do mercado, bem como de ensino-aprendizagem estarão fortemente associados ao conceito de competência. De acordo com as possíveis mudanças desencadeadas pelas novas diretrizes, aponta-se que a formação médica deve garantir a interação entre profissionais de saúde, usuários, estudantes e professores ${ }^{1}$.
Assim sendo, deve-se avaliar permanentemente a maneira como essa mudança curricular tem-se efetivado na prática e de que forma os sujeitos dessa mudança - estudantes, corpo docente, administração e sociedade - discutem, refletem e aplicam a reforma curricular.

Nesse contexto, o plano de ação de uma disciplina pode refletir a maneira como as diretrizes curriculares serão desenvolvidas naquela determinada disciplina e até mesmo como o próprio curso se desenvolverá à luz das disciplinas que o compõem. Desse modo, os planos podem clarificar como o perfil do médico egresso proposto pelas DCN é contemplado pelas disciplinas e como esses elementos do aprendizado baseado em competências são efetivados na prática.

Este artigo tem como objetivo analisar o conteúdo dos Planos de Ação das disciplinas do currículo de um curso de Medicina, tendo como referência as competências/habilidades propostas para o curso médico. Especificamente, objetiva correlacionar as competências/habilidades das DCN com os períodos/semestres da graduação em que são desenvolvidas.

\section{MÉTODO}

A base empírica desta pesquisa foi constituída por 70 Planos de Ação das disciplinas de um curso de Medicina de uma universidade filantrópica do Sul do Brasil, do ano de 2010, e o documento das DCN para o curso de Medicina ${ }^{4}$, totalizando 71 documentos.

Na organização e análise do material utilizou-se Análise de Conteúdo ${ }^{7}$, que contempla três etapas: pré-análise; exploração do material; e tratamento dos resultados, inferência e interpretação.

Na pré-analise, o material foi preparado para composição de corpus para análise, selecionando: das DCN, o rol de competências que o documento propõe; e dos Planos de Ação, o item com as informações sobre as "competências e habilidades" para o egresso do curso de Medicina e ementário da disciplina.

Na exploração do material, analisaram-se a ocorrência e a verificação de igualdades entre os 71 documentos. Nesta fase, foi utilizado o software PorOnto ${ }^{8}$, que auxiliou na extração de termos simples ou compostos dos documentos, identificando a ocorrência dos mesmos termos.

O PorOnto é uma tecnologia desenvolvida no Programa de Pós-Graduação em Tecnologia em Saúde (PPGTS), para a construção semiautomática de ontologias em português. $\mathrm{O}$ processo de construção semiautomática é dividido em duas etapas: a criação do corpus e a criação da ontologia. Nesta pesquisa, o referido software foi utilizado apenas em seu primeiro recurso, ou seja, a composição do corpus. 
Para ser processado, o texto completo deve ser preparado em arquivo texto, dividido por espaços; as Stop Words — palavras, geralmente funcionais, que não devem ser consideradas na composição de termos - são removidas. O PorOnto processa o texto peloTreeTagger, um recurso de anotação linguística no qual as palavras são anotadas com a classe gramatical e o lema, a forma canônica da palavra.

Os termos compostos foram extraídos conforme as regras expressas de sequência de tipos morfológicos "Substantivo e Adjetivo", "Substantivo, Preposição e Substantivo", "Substantivo, Preposição, Adjetivo, Substantivo" e "Substantivo, Preposição, Substantivo, Preposição, Substantivo". Também foi utilizado o recurso, disponível pelo software, de busca por sinônimos dos termos na lista do OpenThesaurusPT, que se trata de um dicionário de sinônimos para a língua portuguesa, com 13.256 palavras e 4.102 sinônimos.

Após processados pelo software, os termos foram transportados para planilhas do Microsoft Excel ${ }^{\circledR}$, conforme frequência de palavras e termos presentes nas DCN e nos Planos de Ação.

Para identificar se os termos selecionados eram relevantes e fundamentais para descrever cada uma das competências individualmente, a etapa de seleção foi complementada pela leitura exaustiva de todos os documentos, de forma a verificar o contexto da existência do termo no documento. Nesta apreciação, foi considerada não somente a palavra literal, como também cada um de seus sinônimos e sentidos das expressões.

A fase de tratamento dos resultados, inferência e interpretação iniciou-se com a correlação dos termos das competências das DCN com as competências dos Planos de Ação. Para isso, os termos foram reorganizados em planilha Microsoft Excel ${ }^{\circledR}$.

Os termos presentes nas DCN cujo significado foi correlacionado às competências foram procurados na lista de termos dos Planos de Ação, usando-se as seguintes classificações: (a) competência presente: deveria conter os termos referentes a ela ou palavras que, contextualizadas, representassem aquelas competências; (b) competência ausente: não contém termo que represente ou contextualize aquelas competências; (c) parcialmente presente: a competência estava presente, mas não cumpria a maioria dos requisitos das DCN. Parte destes resultados foi demostrada em estatísticas simples e frequências absolutas.

A análise das competências/habilidades e sua correlação com as DCN foram realizadas por disciplinas pontuais, por semestres e por fases do curso. A análise de conteúdo permitiu a emergência de categorias interpretativas, e a discussão foi sustentada pela literatura pertinente ao assunto.

Esta pesquisa faz parte do projeto "Proposta de uma ferramenta computacional para apoio ao processo avaliativo das competências do estudante do curso de Medicina", aprovado pelo Comitê de Ética em Pesquisa da PUCPR, sob o Parecer $\mathrm{n}^{\mathrm{o}}$ 0004944/11

\section{RESULTADOS}

As DCN são compostas por 28 competências e habilidades, sendo que seis delas são gerais, comuns para os cursos de Medicina, Enfermagem e Nutrição, e 22 são específicas para o curso de Medicina. As competências/habilidades gerais foram identificadas por números arábicos, e as competências / habilidades específicas por números romanos (Quadro 1).

\section{QUADRO 1}

Descrição de cada competência proposta pelas Diretrizes

Curriculares

\begin{tabular}{|c|c|}
\hline Competência & Descrição da Competência \\
\hline 1 & Atenção à saúde. \\
\hline 2 & Tomada de decisões. \\
\hline 3 & Comunicação. \\
\hline 4 & Liderança. \\
\hline 5 & Administração e gerenciamento. \\
\hline 6 & Educação permanente. \\
\hline I & $\begin{array}{l}\text { Promover estilos de vida saudáveis, conciliando as } \\
\text { necessidades tanto dos seus clientes/paci- } \\
\text { entes quanto às de sua comunidade, atuando como } \\
\text { de agente de transformação social. }\end{array}$ \\
\hline II & $\begin{array}{l}\text { Atuar nos diferentes níveis de atendimento à } \\
\text { saúde, com ênfase nos atendimentos primário e } \\
\text { secundário. }\end{array}$ \\
\hline III & $\begin{array}{l}\text { Comunicar-se adequadamente com os colegas de } \\
\text { trabalho, os pacientes e seus familiares. }\end{array}$ \\
\hline IV & $\begin{array}{l}\text { Informar e educar seus pacientes, familiares e } \\
\text { comunidade em relação à promoção da saúde, } \\
\text { prevenção, tratamento e reabilitação das doenças, } \\
\text { usando técnicas apropriadas de comunicação. }\end{array}$ \\
\hline V & $\begin{array}{l}\text { Realizar com proficiência a anamnese e a } \\
\text { consequente construção da história clínica, bem } \\
\text { como dominar a arte e a técnica do exame físico. }\end{array}$ \\
\hline VI & $\begin{array}{l}\text { Dominar os conhecimentos científicos básicos da } \\
\text { natureza biopsicossocioambiental subjacentes } \\
\text { à prática médica e ter raciocínio crítico na } \\
\text { interpretação dos dados, na identificação da } \\
\text { natureza dos problemas da prática médica e na sua } \\
\text { resolução. }\end{array}$ \\
\hline VII & $\begin{array}{l}\text { Diagnosticar e tratar corretamente as principais } \\
\text { doenças do ser humano em todas as fases do ciclo } \\
\text { biológico, tendo como critérios a prevalência e } \\
\text { o potencial mórbido das doenças, bem como a } \\
\text { eficácia da ação médica. }\end{array}$ \\
\hline
\end{tabular}


Reconhecer suas limitações e encaminhar,

VIII adequadamente, pacientes portadores de problemas que fujam ao alcance da sua formação geral.

Otimizar o uso dos recursos propedêuticos,

IX valorizando o método clínico em todos seus aspectos.

Exercer a medicina utilizando procedimentos

$X \quad$ diagnósticos e terapêuticos com base em evidências científicas.

Utilizar adequadamente recursos semiológicos e terapêuticos, validados cientificamente,

XI contemporâneos, hierarquizados para atenção integral à saúde, no primeiro, segundo e terceiro níveis de atenção.

Reconhecer a saúde como direito e atuar de forma a garantir a integralidade da assistência, entendida como conjunto articulado e contínuo

XII de ações e serviços preventivos e curativos, individuais e coletivos, exigidos para cada caso em todos os níveis de complexidade do sistema.

Atuar na proteção e na promoção da saúde e na prevenção de doenças, bem como no tratamento e reabilitação dos problemas de saúde e acompanhamento do processo de morte.
Realizar procedimentos clínicos e cirúrgicos indispensáveis para o atendimento ambulatorial e para o atendimento inicial das urgências e emergências em todas as fases do ciclo biológico.

Conhecer os princípios da metodologia científica, possibilitando-lhe a leitura crítica de artigos técnico-científicos e a participação na produção de conhecimentos.

Lidar criticamente com a dinâmica do mercado de trabalho e com as políticas de saúde.

Atuar no sistema hierarquizado de saúde,

XVII obedecendo aos princípios técnicos e éticos de referência e contrarreferência.

Cuidar da própria saúde física e mental e buscar seu bem-estar como cidadão e como médico.

Considerar a relação custo-benefício nas decisões XIX médicas, levando em conta as reais necessidades da população.

Ter visão do papel social do médico e disposição

XX para atuar em atividades de política e de planejamento em saúde.

XXI Atuar em equipe multiprofissional.

XXII Manter-se atualizado com a legislação pertinente à saúde.

\section{QUADRO 2}

Distribuição das competências por semestres

\begin{tabular}{|c|c|c|c|c|c|c|c|c|c|c|c|c|c|c|c|c|c|c|c|c|c|c|c|c|c|c|c|}
\hline Semestre & 1 & 2 & 3 & 4 & 5 & 6 & $\mathbf{I}$ & II & III & IV & $\mathbf{V}$ & VI & VII & VIII & IX & $x$ & XI & XII & XIII & XIV & $\mathbf{X V}$ & XVI & XVII XVIII XIX & $X X$ & XXI & XXII & Total/C \\
\hline $1^{\circ}$ & & & & & & & & & & & & & & & & & & & & & & & & $x$ & & & 1 \\
\hline $2^{\circ}$ & & & & & & & & & & & & & & & & & & & $x$ & & & $x$ & & & & & 2 \\
\hline $3^{\circ}$ & & & & & & & & & $x$ & & $x$ & & $x$ & & & & & & & & & & & & & & 3 \\
\hline $4^{\circ}$ & & & & & & & & & & & $x$ & $x$ & & & & & & & & & $x$ & & & & & & 3 \\
\hline $5^{\circ}$ & & & & & & & & & $x$ & & $x$ & $x$ & $x$ & & & & & & $x$ & & $x$ & & & & $x$ & $x$ & 8 \\
\hline $6^{\circ}$ & & & & $x$ & & & & $x$ & & & $x$ & $x$ & $x$ & & & $x$ & $x$ & & & $x$ & $x$ & $x$ & & & & $x$ & 11 \\
\hline $7^{\circ}$ & $x$ & & & & & & & & & $x$ & $x$ & $x$ & $x$ & & & & & & $x$ & & $x$ & & & $x$ & & & 8 \\
\hline $8^{\circ}$ & & & & & & & & & & & $x$ & & $x$ & & & $x$ & & & & $x$ & $x$ & $x$ & & & $x$ & $x$ & 8 \\
\hline $9^{\circ}$ & $x$ & & & & & & & & & $x$ & $x$ & & $x$ & & $x$ & & & & $x$ & & $x$ & & & & & & 7 \\
\hline $10^{\circ}$ & $x$ & $x$ & & & $x$ & & & & & & $x$ & $x$ & $x$ & $x$ & $x$ & & & & & $x$ & & $x$ & $x$ & & $x$ & & 12 \\
\hline $11^{\circ}$ & $x$ & & & & $x$ & & & $x$ & & $\mathrm{x}$ & $x$ & & $x$ & $x$ & $x$ & & & & $x$ & $x$ & $x$ & $x$ & & & & & 12 \\
\hline $12^{\circ}$ & $x$ & & & & & & $x$ & & $x$ & & $x$ & $x$ & $x$ & $x$ & & $x$ & & & $x$ & $x$ & & $x$ & & $x$ & $x$ & $x$ & 14 \\
\hline
\end{tabular}


Na comparação entre os termos levantados pelo PorOnto nas DCN e nos Planos, havia um total de 24 competências / habilidades das DCN distribuídas em 68 disciplinas. Após a leitura de cada Plano e comparação com as DCN, foi identificado que 23 competências/habilidades estavam presentes em 62 disciplinas.

A ocorrência das competências/habilidades das DCN por semestre do curso de Medicina variou de 1 até 14 (Quadro 2). A distribuição média de competências em cada disciplina por semestre variou de 0,5 até 4 competências (Gráfico 1).

A letra $x$ indica que determinada competência esteve presente naquele semestre de acordo com os Planos de Ação. "Total/S" indica quantos semestres apresentam aquela competência das DCN. "Total/C" indica quantas competências estavam presentes naquele semestre.

\section{GRÁFICO 1}

Média do número de competências em cada disciplina por semestre

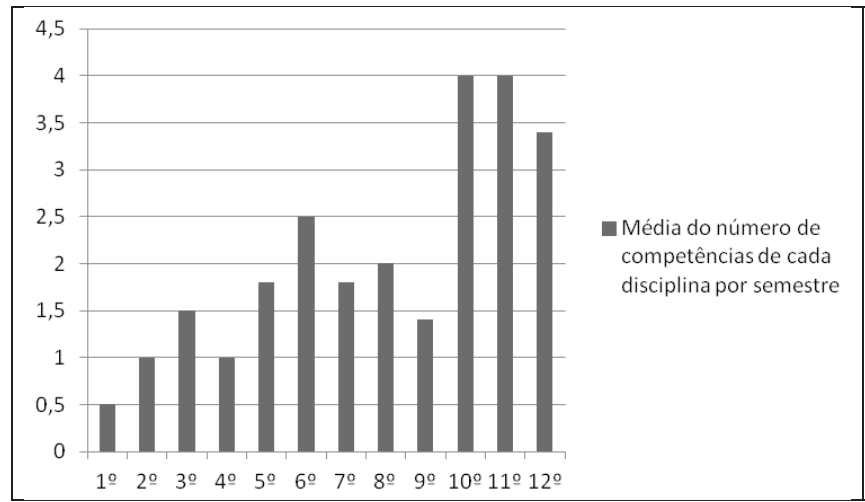

Ao separar os semestres nas três fases do curso de Medicina da Universidade - fase pré-clínica (primeiro ao quarto semestre), fase clínica (quinto ao nono) e internato (10ำ ao $12^{\circ}$ ) (Quadro 3) -, obteve-se uma progressão das competência/habilidades de acordo com a progressão do curso, sendo que a distribuição média de competências em cada disciplina por fase foi, respectivamente, 0,9, 2 e 3,8.A disciplina que aparece com maior frequência está relacionada com a Atenção Primária à Saúde, presente em nove de 12 semestres.

\section{DISCUSSÃO}

\section{Modelo de descrição do Plano de Ação}

Foi possível observar que muitos Planos de Ação das disciplinas continham uma descrição dos temas que seriam abordados (conteúdo técnico) e não uma descrição das competências e habilidades (objetivo), sendo estas sucintamente mencionadas. Dentre as 70 disciplinas do curso, oito não apresentaram competências relacionadas às competências sugeridas pelas DCN. Dessas oito, seis não apresentavam sequer o item competências, estando dispostos conteúdos programáticos. A presença de competências em 62 Planos de Ação indica que $88,6 \%$ das disciplinas estão coerentes com as propostas das DCN, e apenas $8,6 \%$ não estão adequadas à proposta das diretrizes.

Embora tenha sido observado que a grande maioria das disciplinas teve seus Planos de Ação voltados para competências, algumas delas apresentaram enfoque em conteúdos, e em algumas disciplinas não houve a descrição do seu objetivo. A ausência do objetivo na constituição do Plano de Ação pode descaracterizar a relevância dos assuntos abordados para a profissão, da mesma forma que pode assumir caráter repetitivo, tendo em vista que algumas disciplinas podem discutir o mesmo tema, competência ou habilidade com o mesmo enfoque, ocorrendo a teorização da prática?.

É fundamental, portanto, a iniciativa não somente dos docentes, mas também das Instituições de Ensino Superior (IES) para a garantia de educação permanente na formação pedagógica de seus professores. São funções das IES: apoiar, incentivar, avaliar e discutir com seus docentes e estudantes qual o médico que desejam formar, garantindo o desempenho adequado de seus papéis.

QUADRO 3

Competências presentes em cada fase do curso

\begin{tabular}{|c|c|c|c|c|c|c|c|c|c|c|c|c|c|c|c|c|c|c|c|c|c|c|c|c|c|c|}
\hline Fase & 1 & 2 & 3 & 45 & 56 & I & II & III & IV & $\mathrm{V}$ & VI & VII & VIII & IX & $x$ & XI XII & XIII & XIV & $X V$ & XVI & XVII & XVIII & XIX & $X X$ & $X X I$ & XXII \\
\hline P. clínica & & & & & & & & $X$ & & $x$ & $X$ & $X$ & & & & & $X$ & & $x$ & $X$ & & & & $X$ & & \\
\hline Clínica & $x$ & & & $X$ & & & $x$ & $x$ & $x$ & $x$ & $x$ & $X$ & & $x$ & $x$ & $x$ & $X$ & $X$ & $x$ & $X$ & & & & $X$ & $x$ & $x$ \\
\hline Internato & $X$ & $X$ & & $X$ & $x$ & $X$ & $X$ & $x$ & $X$ & $X$ & $x$ & $X$ & $X$ & $x$ & $X$ & & $X$ & $X$ & $x$ & $X$ & $X$ & & & $X$ & $x$ & $X$ \\
\hline
\end{tabular}

A letra $\mathrm{X}$ indica as competências/habilidades que estão presentes em cada fase do curso médico. 
Entre as estratégias para a elaboração de um projeto pedagógico claro para o estudante, está a participação do discente e do docente na formulação do processo didático. Essa participação pode ter como resultado a superação da visão tecnicista, o comprometimento destes estudantes com a prática docente e com o ensino e a importância da formação docente na universidade $^{10}$.

Desse modo, o que se viu nos Planos de Ação com a orientação para competências pode estar relacionado com a formação pedagógica do professor ${ }^{10}$ na elaboração do seu Plano de Ação, voltado a competências ${ }^{11}$.

\section{Competências presentes nos Planos de Ação}

Analisando-se os Quadros 2 e 3, observa-se que 23 das 28 competências propostas pelas DCN estão presentes nos Planos de Ação, e, destas, oito estão presentes em todas as fases do curso. $\mathrm{O}$ aumento gradativo de competências no decorrer das fases também indica que se espera que o estudante consiga desenvolver habilidades/competências de forma processual e contínua. Todas as competências com caráter tecnicista foram contempladas pelos Planos de Ação.

As competências que aparecem com maior frequência nos Planos de Ação são as competências V e VII. Elas se referem principalmente a conhecimentos técnicos, que são essenciais à formação médica.

O diagnóstico e o tratamento são funções inerentes à profissão médica, devendo ser desenvolvidos de maneira magistral durante o curso de graduação. $\mathrm{O}$ conteúdo técnico é importante, mas isoladamente é insuficiente para que o estudante tenha o entendimento de casos complexos reais, que não se apresentam por especialidades médicas, sendo, portanto, necessárias outras competências que garantam o adequado aprendizado.

Competências que propõem a criação de vínculo e empatia ou ser cuidador estão diretamente relacionadas em muitas competências das DCN, como em: 5 (administração e gerenciamento), I (promover estilos de vida saudáveis), III (comunicação adequada), VI (dominar os conhecimentos científicos de ordem biopsicossocioambiental)e XI (utilizar adequadamente recursos semiológicos e terapêuticos). Observa-se, de forma geral,que essas competências/habilidades estavam presentes nos Planos de Açãodo currículo avaliado.

\section{Competências ausentes nos Planos de Ação}

Analisando-se o Quadro 1, nota-se que cinco das 28 competências não estão contidas de forma integral em nenhuma das disciplinas, sendo: a) Competência 3: “[...] ser acessíveis e devem manter a confidencialidade das informações a eles confiadas, na interação com outros profissionais de saúde e o público em geral[...]";

b) Competência 6: "[...] os profissionais de saúde devem aprender a aprender e ter responsabilidade e compromisso com a educação e o treinamento[...]";

c) Competência XII: "[...]atuar de forma a garantir a integralidade da assistência entendida como conjunto articulado e contínuo de ações[...]";

d) Competência XVIII: “[...]buscar seu bem-estar como cidadão e como médico";

e) Competência XIX: “Considerar a relação custo-benefício nas decisões médicas, levando em conta as reais necessidades da população."

Observa-se que são competências que requerem dos estudantes elevado grau de crítica, capacidade de compreender as necessidades da sociedade e de si. Propõem que o estudante seja ativo em sua formação e desenvolva o "saber ser".

A ausência dessas competências pode ser considerada pela limitação de analisar temas tão complexos somente através dos Planos de Ação das disciplinas de um curso, entendendo que a complexidade deve ser analisada de forma multivariada ${ }^{12}$.

\section{A Educação Permanente e o cuidar de si}

A IES avaliada desenvolve sua metodologia de ensino mediante aulas expositivas e sessões tutoriais que utilizam a Aprendizagem Baseada em Problemas. Desse modo, há uma vital importância nos questionamentos do estudante no desenvolvimento da aprendizagem, tanto individual quanto coletiva ${ }^{13}$. Assim sendo, o estudante é responsável por aprender a aprender.

A ausência da Educação Permanente (competência 6) nos Planos pode estar ligada a uma fragilidade do seu desenvolvimento nas disciplinas. No entanto, a própria metodologia empregada pelo curso pressupõe um processo ativo de ensino e aprendizagem.Desse modo,talvez por serinerente à metodologia, os docentes não sentiram necessidade de destacá-la em seus Planos. Mesmo assim, deve-se atentar para a relevância dessa competência, uma vez que a educação deve garantir que o futuro profissional seja capaz de desenvolver autonomia e apresente grande capacidade de incremento do coletivo ${ }^{14}$.

Outro ponto importante, que é o cuidado do profissional (competência XVIII), não é destacado pelos Planos de Ação. No entanto, aprender a cuidar de si e promover seu bem-estar deve fazer parte das competências e habilidades desenvolvidas ${ }^{15}$.

\section{A integralidade}

A integralidade é outro ponto de destaque na formação, trazendo uma linha de cuidado que considera ações coordenadas 
para benefício do sujeito. Desse modo, é apontada como um dos principais elementos de um currículo baseado em competências, associado ao Sistema de Saúde (SUS) e à universida$\mathrm{de}^{10}$. Nesse cenário, a Atenção Primária à Saúde é destacada pelo Ministério da Educação ${ }^{4,16}$ como norteadora dessa prática integral. Apesar disso,notam-se entraves na comunicação entre as instituições formadoras e o SUS ${ }^{10}$.

Observam-se alguns avanços propostos pelo governo federal para a melhoria desta interlocução, a exemplo do Pró-Saúde,que tem como objetivo tornar as IES e os serviços de saúde vinculados ao SUS mais próximos para transformar o aprendizado, deixando-o condizente com a realidade social e econômica da população brasileira ${ }^{16}$.

Mesmo com tais iniciativas do governo federal, as parcerias entre Estados e municípios são realizadas de forma optativa e particularizada, dependendo de cada esfera a sua otimização. Em muitos casos, elas ocorrem de forma saudável e recompensadora, como no caso do Pró-Saúde ${ }^{16}$, porém é percebido que, em outros casos, a formação e a gestão de recursos humanos em saúde são desconsideradas por gestores em todas as esferas no Brasil ${ }^{17}$.

Há uma preocupação da instituição de ensino que teve seus Planos de Ação avaliados com a presença da APS em nove dos 12 semestres do curso, bem como do Ministério da Educação em estabelecer parcerias e fomentar a integralidade. Apesar de a integralidade com seu amplo conceito não ter sido observada, nota-se que algumas disciplinas buscam integrar algumas ações especializadas e focadas em conteúdo, mas que podem ser um embrião para a integralidade na formação ${ }^{13}$. Isto é notado no fragmento:"Aplicar a técnica de entrevista médica focada nos pacientes com doenças psiquiátricas e infectocontagiosas. Executar exame físico geral e específico nos pacientes com doenças psiquiátricas e infectocontagiosas".

Sendo assim, é importante buscar uma correlação entre as diferentes áreas do conhecimento, uma vez que o sujeito é integral. Um estímulo para isso é a interdisciplinaridade com o objetivo de considerar tanto o cuidado, como a integralidade, o controle social, a humanização, a ética, as abordagens e as pesquisas disciplinares com o mesmo grau de importância ${ }^{18}$.

A ausência da competência XII remete à preocupação de que o conteúdo técnico é importante, mas isoladamente é insuficiente para que o estudante tenha o entendimento de casos complexos reais, que não se apresentam por especialidades médicas ${ }^{13}$, devendo ser perseguido o desenvolvimento desta competência. Entretanto, a presença da APS em nove semestres do curso pode apontar a importância da integralidade no currículo do curso.

\section{Avaliação do risco-benefício e das necessidades do sujeito}

O cuidado não depende somente de desenvolver habilidades para o ato de cuidar. Para a concretização deste, deve-se antes reconhecer o que é importante para si e quais são as reais necessidades de saúde para o sujeito, sua família e comunidade. O profissional de saúde, ao perfilhar seus valores, crenças e papéis, consegue respeitar-se e respeitar o outro. Neste sentido, cabe ao docente auxiliar o estudante a desenvolver as melhores condições para viver e possibilitar que o próximo viva com qualidade pautada na moral e na ética ${ }^{19}$.

O cuidar deve ser incentivado em todos os momentos durante a graduação médica, e, para que o cuidado em saúde seja efetivado, são necessários cenários adequados de atenção, bem como ajustamentos dos modos de atenção relacionados à formação e à capacitação ${ }^{20}$.

Ao estudar a relação médico-paciente e a tarefa de individualizar as ações para os pacientes durante o curso de Medicina, é necessário observar o perigo do excesso de teorização, pois esta pode diminuir a importância do cuidar, enfocando somente o tratar, com a visão na doença e não na pessoa ${ }^{21}$. Esse excesso de teorização poderia afastar os estudantes de uma visão integral socialmente responsável, uma vez que o reducionismo do tratar é insuficiente para a compreensão ampla do sujeito e da sociedade.

É crítica evidenciada a primazia da Medicina Baseada em Evidências, que, por um lado, utiliza os melhores recursos clínicos, mas, por outro, pode levar o estudante a resolver problemas buscando a única resposta correta, deixando de refletir sobre questões mais profundas, como seu papel de cuidador ${ }^{22}$. Desse modo, a falta da competência XIX poderia influenciar o processo de cuidado, renegando o papel de um importante agente desse processo, o próprio médico.

\section{As competências e as fases do curso}

Os semestres iniciais do curso apresentam menor concentração de competências em comparação aos mais avançados. Uma vez que o desenvolvimento é constante durante o curso, essa verificação pode ser esperada. No entanto, deve-se ficar atento, pois a prática do cuidar pode ser substituída pela técnica de curar, levando a profissionais menos humanizados ${ }^{16}$. Uma estratégia seria a elaboração de um eixo humanístico através de uma proposta de Integração de Humanidades no Currículo Médico ${ }^{22,23}$.

O desenvolvimento das competências deve ser gradual e acumulativo ao longo dos semestres formativos,tanto auxiliando a aquisição de novas competências técnicas, como realizar a história clínica e o exame físico, como permitindo que este estudante mantenha e desenvolva habilidades/com- 
petências mais utilizadas no início da vida acadêmica, como a empatia e a ética.

Só é considerado importante aquilo que se oferece com representação para o estudante. Deste modo, algumas competências/habilidades devem ser estimuladas desde o início do curso, por mais que não sejam completamente desenvolvidas. Se não houver, desde os primeiros semestres da graduação,o indicativo da importância do trabalho em um sistema hierarquizado, em equipe multidisciplinar, preocupando-se com educação permanente, sendo ativo, líder, responsável socialmente, há grandes possibilidades de o estudante não conseguir realizar essas ações após a graduação, pois seu olhar poderá estar limitado à medicina estritamente curativa. Para a transformação dos cursos médicos, deve-se pensar no conceito ampliado de saúde, na integralidade, no cuidado e no trabalho em equipe multiprofissional para inspirar projetos inovadores que mudem seus processos de trabalho ${ }^{18}$.

Enfatiza-se também a necessidade não somente deintegrar as disciplinas e as fases do curso médico, como também de compreender as diferentes perspectivas que representam esta forma de currículo para os docentes, os discentes e as IES, garantindo o efetivo redesenho do currículo médico ${ }^{24}$.

\section{CONCLUSÃO}

Diante dos resultados obtidos, observa-se que a IES analisada construiu os Planos de Ação de suas disciplinas guiados por competências, pois a grande maioria das competências está contemplada no currículo da universidade.

As competências ligadas a habilidades específicas, como a realização de anamnese e o exame físico, aparecem em uma porcentagem maior de disciplinas;por outro lado, competências como aquelas ligadas à integralidade fazem parte de um número menor de discuplinas. Esse fato pode ser explicado por algunsfatores. É extremamente importante e espera-se que o egresso apresente algumas competências específicas, sem as quais não exerceria a medicina. Além disso, como a análise foi feita com base em Planos de Ação, esse tipo de competência é mais fácil de ser explicitada em uma linguagem escrita do que outras menos objetivas.

Entretanto, deve-se estimular que competências amplas - como as ligadas à integralidade, ser acessível ao paciente, responsabilidade, compromisso, levar em conta as necessidades da população e o cuidar de si — façam parte do cotidiano do ensino e aprendizagem. A ausência dessas competências não quer dizer que necessariamente estejam ausentes no ensino, mas por algum motivo não foram explicitadas nos Planos. Isso pode ocorrer por estarem associadas a competências bastante complexas para serem transportadas para uma linguagem escrita, estando mais ligadas a atividades práticas e atitudes.

Nesse sentido, as IES devem apoiar, incentivar e demandar a formação pedagógica do docente, assim como fortificar e aproximar as relações com os órgãos gestores do sistema de saúde para garantir a adequação da formação médica ${ }^{24}$, integrando todas as competências e habilidades necessárias ao egresso médico.

As reformas curriculares que ocorreram a partir das DCN visaram aproximar o estudante de Medicina da sociedade e do sistema de saúde brasileiro. Para que essa mudança ocorra, é necessário que as IES, seu corpo docente, os governantes e a sociedade atentem para fatores que influenciam a qualidade do profissional da saúde.

Entre estes fatores vale ressaltar os paradigmas que estão presentes, tanto o da complexidade quanto o paradigma tradicional newtoniano-cartesiano, os valores éticos e morais, as relações de poder que envolvem todas as esferas tanto da saúde quanto da educação, além das características psicológicas do estudante de Medicina.

O observado neste trabalho aponta um currículo em sua grande maioria pautado por competências/habilidades, com o desenvolvimento gradual destas durante as fases do curso médico, tendo a APS como um grande eixo que percorre nove dos 12 semestres do curso; preocupado com as competências técnicas do egresso, sem se ausentar do papel social da universidade, bem como da relação médico-paciente, do cuidado e do trabalho multiprofissional.Dessa forma, pode-se notar que o modelo curricular e a presença das competências apontadas pelas DCN assinalam a inserção da instituição nas inovações propostas pelo ensino médico. Abre-se um questionamento e a proposição de trabalhos futuros sobre o impacto dessas propostas dos Planos de Ação no processo de ensino e aprendizagem, bem como nos estudantes do curso de Medicina.

\section{REFERÊNCIAS}

1. Nogueira MI. As mudanças na educação médica brasileira em perspectiva: reflexões sobre a emergência de um novo estilo de pensamento. Rev. Bras. Educ. Med [online]. 2009; 33(2). [Capturado 09 mai. 2010]. Disponível em: <http:/ / www.scielo.br/pdf/rbem/v33n2/14.pdf>

2. Siqueira-Batista R, Siqueira-Batista R. Os anéis da serpente: a aprendizagem baseada em problemas e as sociedades de controle. Ciênc. Saúde Coletiva. 2009; 14(4). [Capturado 23 jun. 2010]. Disponível em:<http:/ / www.scielo.br/pdf/ csc/v14n4/a19v14n4.pdf>

3. Lafuente JV, Escaneiro JF, Manso JM, Mora S, Miranda $\mathrm{T}$, Castillo $\mathrm{M}$, et al. El diseño curricular por compe- 
tencias en educación médica: impacto en la formación profesional. Educ. Méd [on line]. 2007; 10(2): 86-92 [capturado 29 abr. 2010]. Disponível em: <http://scielo.isciii.es / scielo.php?script=sci_arttext\&pid=S1575$-18132007000300004 \& \operatorname{lng}=\mathrm{es}>$

4. Brasil. Ministério da Educação. Conselho Nacional de Educação. Câmara de Educação Superior. Resolução CNE/CES nº4 de 7 de novembro de 2001. Institui diretrizes curriculares nacionais do curso de graduação em Medicina. Diário Oficial da União. Brasília, 9 nov. 2001; Seção 1, p.38.

5. Yániz C. Las competencias en el currículo universitario: implicaciones para diseñar el aprendizaje y para la formación del profesorado. Revista docência universitária [online]. 2008; [capturado 15 out. 2010] Disponível em: <http:/ / revistas.um.es/redu/article/view/10621/10211>

6. González Agudelo EM, Díaz Hernández DP. Desde el currículo hasta la didáctica o sobre la circulación de los saberes y sus controles en la universidad: un ejemplo en la enseñanza de la Medicina. Iatreia [online]. 2008; 21(1) [capturado 11 mai. 2010]; 83-93. Disponível em: <http:/ / www. scielo.org.co/scielo.php?script=sci_arttext\&pid=S0121$-07932008000100010 \& \operatorname{lng}=\mathrm{en}>$

7. Bardin L. Análise de conteúdo. Lisboa: Edições 70; 1995.

8. Zahra FM. Poronto: ferramenta para construção semiautomática de ontologias em português. Curitiba; 2009. Mestrado [dissertação] — Pontifícia Universidade Católica do Paraná.

9. Ciuffo RS, Ribeiro VMB. Sistema Único de Saúde e a formação dos médicos: um diálogo possível?Interface [online]. 2009; 12(24) [capturado 18 ago. 2011]; 125-140. Disponível em: <http://www.scielo.br/pdf/icse/v12n24/09.pdf>

10. Costa NMSC. Docência no ensino médico: por que é tão difícil mudar?. Rev. Bras. Educ. Med [online]. 2007; 31 (1) [capturado 01 fev. 2012]; 21-30. Disponível em: <http:// www.scielo.br/pdf/rbem/v31n1/04.pdf>

11. Foresti MCPP, Pereira MLT. Qualidade da docência universitária e formação docente em programas de pós graduação em saúde: a experiência da Unesp, campus Botucatu. In: Batista N A, Batista SHSS, org. Docência em saúde: temas e experiências. São Paulo: Senac; 2004. p. 210-223.

12. Batista NA, Batista SHSS. Docência em saúde: temas e experiências. São Paulo: Senac; 2004.

13. Mitre SM, Siqueira-Batista R, Girardi-de-Mendonça JM, Morais-Pinto NM, Meirelles CAB, Pinto-Porto C, et al. Metodologias ativas de ensino-aprendizagem na formação do profissional em saúde: debates atuais. Ciências\&Saúde Coletiva 2008; 13(2): 2133-2144.
14. Marins JJN. Os cenários de aprendizagem e o processo do cuidado em saúde. In: Marins JJN, Rego S, Lampert JB, Araújo JGC, org. Educação Médica em transformação: instrumentos para a construção de novas realidades. São Paulo: Hucitec; 2004. p.97-108.

15. Marins JJN. Os cenários de aprendizagem e o processo do cuidado em saúde. In: Marins JJN, Rego S, Lampert JB, Araújo JGC, org. Educação Médica em transformação: instrumentos para a construção de novas realidades. São Paulo: Hucitec; 2004. p.97-108.

16. Assuncão LF, Melo GCMP, Maciel D. Relação médico-paciente permeando o currículo na ótica do estudante. Rev Bras Educ Med [online]. 2008; 32(3) [capturado 16 out.2011]; 383-389. Disponível em: <http://www.scielo. $\mathrm{br} / \mathrm{pdf} / \mathrm{rbem} / \mathrm{v} 32 \mathrm{n} 3 / \mathrm{v} 32 \mathrm{n} 3 \mathrm{a} 13 . \mathrm{pdf}>$

17. Brasil. Ministério da Saúde. Ministério da Educação. Programa Nacional de Reorientação da Formação Profissional em Saúde - Pró-Saúde: objetivos, implementação e desenvolvimento potencial. Brasília: Ministério da Saúde; 2007b.

18. Almeida LVG, Ferraz CA. Políticas de formação de recursos humanos em saúde e enfermagem. Rev. Bras. Enferm [online]. 2008; 61(1) [capturado 01 mar. 2012]; 31-35. Disponível em: <http://www.scielo.br/pdf/reben/v61n1/05.pdf> 19. Merhy EE. Saúde: a cartografia do trabalho vivo. São Paulo: Hucitec; 2007.

19. Antonello ICF. Cuidando de Cuidadores em formação nas faculdades de medicina. Bioética 2006; 14(2):159-162.

20. Batista N, Batista SH, Goldenberg P, Seiffert O, Sonzogno MC . O enfoque problematizador na formação de profissionais da saúde. Rev. Saúde Pública [online]. 2005; 39 (2) [capturado 12 fev. 2012]; 231-237. Disponível em: http:/ / www.scielosp.org/pdf/rsp/v39n2/24047.pdf

21. Batistatou A, Doulis $\square$ A, Tiniakos D, Anogiannaki A, Charalabopoulos $\square, 1$. The introduction of medical humanities in the undergraduate curriculum of Greek medical schools: challenge and necessity. Hippokratia [online]. 2010; 14(4) [capturado 02 mar. 2012]; 214-243. Disponível em: <http://www.ncbi.nlm.nih.gov/pmc/articles / PMC3031316/pdf/hippokratia-14-241.pdf>

22. Rios IC. Humanidades e medicina: razão e sensibilidade na formação médica.CiêncSaúde Coletiva [online]. 2010; 15(1) [capturado 10 jan. 2012]; 1725-1732. Disponível em: http://www.scielo.br/pdf/csc/v15s1/084.pdf

23. Muller JH, Jain S, Loeser H, Irby DM . Lessons learned about integrating a medical school curriculum: perceptions of students, faculty and curriculum leaders. Medical Education 2008; 42(8)778-785. 
24. Batista SHS. A interdisciplinaridade no ensino médico. Rev Bras Educ Med [online]. 2006. 30(1) [capturado 03 mar. 2012]; 39-46. Disponível em <http:/ /www.scielo.br/pdf/ rbem/v30n1/v30n1a07.pdf>

\section{CONTRIBUIÇÃO DOS AUTORES}

Todos participaram na elaboração, pesquisa e confecção do artigo.

\section{CONFLITO DE INTERESSES}

Não há conflito de interesses, de qualquer ordem, relacionado a esta pesquisa.
ENDEREÇO PARA CORRESPONDÊNCIA

Camila Ament Giuliani dos Santos Franco

Pontifícia Universidade Católica do Paraná

Rua Imaculada Conceição, 1155

Padro Velho, Curitiba, PR

CEP 80215-901

E-mail: camilaament@gmail.com 